\title{
EFICIÊNCIA DE DEPOSIÇÃO DE PULVERIZAÇÃO EM VIDEIRA, COMPARANDO BICOS E PULVERIZADORES
}

\author{
ALDEMIR CHAIM * \\ MARIA CONCEIÇÃO PERES YOUNG PESSOA ** \\ VERA LÚCIA FERRACINI ***
}

\begin{abstract}
Estudou a deposição de agrotóxicos em videira, proporcionada por diferentes tipos de pulverizadores e de bicos de pulverização. Dois tipos de pulverizadores com ventilador com tomada de ar frontal (Airbus 200 e Airbus 500, fabricados pela Jacto) foram comparados com pulverizador do tipo carreta com ventilador tradicional. O pulverizador tradicional foi regulado com bicos Yamaho D3 e os dois outros pulverizadores com bicos JA-1 ou API-110-015. Para avaliar a eficiência de deposição dos pulverizadores utilizou-se Rodamina B como traçador na calda de pulverização. O equipamento Jacto Airbus 500, equipado com 10 bicos JA-1, regulado para aplicar $246 \mathrm{~L} / \mathrm{ha}$ foi o mais eficiente, depositando $82 \%$ de produto na planta, com perdas de $8 \%$ para o solo e $10 \%$ por evaporação ou deriva.
\end{abstract}

PALAVRAS-CHAVE: TRAÇADOR; AGROTÓXICOS; EQUIPAMENTOS DE PULVERIZAÇÃO.

* Engenheiro Agrônomo, M.Sc. em Tecnologia de Aplicação de Agrotóxicos, Embrapa Meio Ambiente, Jaguariúna, SP (e-mail: aldemir@cnpma.embrapa.br).

** PhD em Automação, Embrapa Meio Ambiente, Jaguariúna, SP (e-mail: young@cnpma.embrapa.br).

** $\quad$ PhD em Química Orgânica, Embrapa Meio Ambiente, Jaguariúna, SP

(e-mail: veraf@cnpma.embrapa.br). 


\section{INTRODUÇÃO}

A principal técnica de aplicação de agrotóxico empregada em videiras, cultivada em latada, caracteriza-se pela utilização de equipamentos tratorizados do tipo carreta com cortina de ar, que projetam as gotas no sentido vertical. Como nesse sistema de cultivo as folhas da parreira desenvolvemse em plano horizontal, teoricamente, somente as folhas da região basal receberiam boa deposição de agrotóxicos. As regiões mediana e superior da latada receberiam doses decrescentes do agrotóxico aplicado. Defeito fácil de ser observado nos pulverizadores com ventiladores é a localização da tomada de ar que, normalmente, situa-se na parte posterior do equipamento. Assim, o ar é sugado pelo ventilador depois da nuvem de gotas gerada pelos bicos. Conseqüentemente, grande parte das gotas com o deslocamento do trator poderia ser sugada pela hélice (efeito de vórtice) reduzindo a deposição na planta.

A modalidade de aplicação de agrotóxico em videira envolve o uso de grandes volumes de calda. A quantidade de depósito de agrotóxico retida pela planta é proporcional à concentração da calda e independe do volume aplicado. Nesse tipo de aplicação, mais de um terço do produto pode atingir o solo (1). Tal fato foi constatado com alguns tipos de equipamentos utilizados em videira cultivada na forma de espaldeira, em que as perdas de produtos para o solo variaram entre 34,5 a 48,9\% (2). Houve casos em que as deposições nas plantas foram superiores a $64 \%$ (3). Em outras culturas também têm sido constatadas perdas apreciáveis de produto como em tomate estaqueado, cuja conformação do cultivo assemelha-se ao da uva em espaldeira. Verificou-se nessa cultura que a porcentagem de agrotóxico depositado variou de acordo com o porte das plantas (entre 24 a 41\%), com perdas para o solo entre 20 a 39\% (4). Quantidades entre 30 e $45 \%$ do produto aplicado não foram encontradas nas plantas ou no solo sendo, provavelmente, perdidos por evaporação ou deriva. Em culturas de porte rasteiro (5) também foram observadas perdas elevadas de agrotóxicos. Na cultura do feijão, dependendo do porte das plantas, a deposição ficou entre 12 e $51 \%$ com perdas para o solo entre 30 e $74 \%$ e deriva/evaporação entre 6 e $39 \%$. Na cultura do tomate rasteiro foi verificado que a deposição variou conforme o porte das plantas, entre 29 e $66 \%$, com perdas para o solo entre 9 e $37 \%$ e perdas por deriva/evaporação entre 16 e $49 \%$. Tem sido constatado que a deposição de agrotóxicos nas plantas não é uniforme $(4,5,6,8)$ em razão de vários fatores, dentre os quais a característica dos bicos e 0 tipo de calibração do equipamento $(6,8)$.

O objetivo deste trabalho foi verificar a deposição de agrotóxicos em videira, cultivada na forma de latada, proporcionada por diferentes tipos de pulverizadores e de bicos de pulverização.

\section{MATERIAL E MÉTODOS}

Foram realizados experimentos para verificar a deposição de agrotóxicos em parreira comercial, com aproximadamente cinco anos de idade, cultivada pelo sistema de latada no sítio Tominaga, localizado no município de Jales (SP). Os experimentos ocorreram nos dias 23 e 24 do mês de junho de 2001.

Para as pulverizações foram usadas caldas aquosas, preparadas no momento da aplicação, com 2,0 gramas/50 litros de Rodamina B p.a. (marca Synth) como traçador. Após a aplicação, amostras de calda foram retiradas para determinação da concentração.

Utilizou-se o delineamento experimental em parcelas subdivididas (9), em que cada parcela principal funcionou como um bloco para os tratamentos das subparcelas. Assim, os níveis dos fatores colocados nas parcelas (denominados tratamentos principais) foram os seguintes: a) deposição na região superior da camada das folhas; b) deposição na região mediana da camada das folhas; c) deposição na região basal da camada de folhas; d) deposição no solo. Os níveis dos fatores casualizados 
nas subparcelas ou tratamentos secundários foram os seguintes: 1) testemunha - pulverizador FMCUVA, equipado com 10 bicos Yamaho D3; 2) pulverizador Jacto Airbus 200, equipado com 14 bicos JA-1;3) pulverizador Jacto Airbus 500, equipado com 10 bicos JA-1;4) pulverizador Jacto Airbus 200, equipado com 14 bicos API 110-015; 5) pulverizador Jacto Airbus 500, equipado com 14 bicos API 110-015.

O pulverizador FMC-UVA do tipo carreta com cortina de ar e tomada de ar pela parte posterior do ventilador foi utilizado como testemunha, devido ao seu emprego tradicional na região. Foram testados os pulverizadores Jacto com tomada de ar frontal ao ventilador, o Airbus 200 montado no terceiro ponto do trator e o Airbus 500 de arrasto do tipo carreta. Os pulverizadores foram calibrados para tratar uma faixa de 2,5 $\mathrm{m}$ de largura em cada passada do equipamento.

O experimento completo foi composto por quatro tratamentos principais, cinco secundários e cinco repetições, resultando em 100 subparcelas. Cada tratamento secundário foi constituído de 9 ruas (2,5 m de largura) com, aproximadamente, 20 metros de comprimento. A pulverização em cada tratamento secundário foi efetuada em três ruas adjacentes para que a amostragem fosse realizada na rua central. Assim, entre os tratamentos secundários de cada bloco foram deixadas seis ruas como bordadura ( $15 \mathrm{~m}$ ). Cada bloco foi constituído por 45 ruas com faixa de 20 metros de bordadura entre os blocos. As subparcelas ficaram separadas umas das outras pela faixa de 20 metros de bordadura.

Para recuperação da deposição utilizou-se sistema de amostragem constituído por cinco cartões mata-borrão $(2,0 \times 10 \mathrm{~cm})$, com gramatura de $250 \mathrm{~g} / \mathrm{m}^{2}$, grampeados de forma espaçada $(0,5 \mathrm{~m}) \mathrm{em}$ barbantes de 2,5 m de comprimento. Foram utilizados cinco barbantes, espaçados em um metro, em cada região da amostragem nas plantas, sendo suas extremidades amarradas nas laterais nas linhas de plantio. Sobre o solo, os cartões foram colocados em discos de Petri para verificação das perdas de pulverização. Em cada tratamento principal foram distribuídos 100 cartões, sendo 25 na região basal, 25 na região mediana, 25 na região apical das plantas e 25 sobre o solo. Em cada bloco foram utilizados 500 cartões de amostragem ou 2500 alvos para todo o experimento.

Após a pulverização de cada tratamento, os alvos foram retirados e embalados num prazo máximo de 10 minutos para evitar possível efeito de degradação, por exposição a radiação solar (7). Durante as coletas, os alvos de cada região de amostragem foram misturados, separando-se aleatoriamente lotes de 5 cartões para composição das amostras das 100 subparcelas para extração da Rodamina B.

A Rodamina B de cada amostra foi extraída em $40 \mathrm{~mL}$ de solução de água e $0,1 \%$ de Tween 80 (polioxietilensorbitano monooleato). Após 15 minutos de agitação, volumes de aproximadamente $3,0 \mathrm{~mL}$ dos extratos das amostras foram adicionados em cubetas de borossilicato para a quantificação em Fluorômetro Turner (Modelo 450). O Fluorômetro, equipado com filtro de excitação NB 540 e filtro de emissão SC 585 (6), foi calibrado segundo métodos já descritos $(6,7)$ para efetuar leitura com resposta linear para a faixa de concentração entre 0 e 1000 microgramas de Rodamina por litro.

Todos os ensaios foram realizados em talhão de uva Itália, podado 65 dias antes da realização do ensaio, que se apresentava com aproximadamente 1,7 $\mathrm{m}$ de altura. Nessa fase, a parreira se encontrava com área foliar média de $17317 \mathrm{~m}^{2} / \mathrm{ha}$. Para estimar a área foliar foi contado o número de folhas por metro quadrado da latada em 20 regiões da parreira. Com esse procedimento constatou-se que havia, em média, 62 folhas $/ \mathrm{m}^{2}$. Foi utilizado o medidor de área foliar LI-COR LI 3100 para medir 100 folhas colhidas, aleatoriamente, na parreira e constatada área média da folha de $279,31 \mathrm{~cm}^{2}$.

A temperatura e a umidade relativa foram monitoradas, durante o experimento, com termohigrômetro (Sper Scientific 800016) e psicrômetro (Assman) com ar aspirado, sendo a velocidade do vento medida com anemômetro manual Davis (modelo Turbo Meter). Esses parâmetros foram observados em carreador ao lado do talhão em que foram realizados os experimentos.

A Tabela 1 apresenta as condições operacionais verificadas nos cinco tratamentos para comparação de pulverização com sistema de ventilação tradicional e pulverização com ventilação modificada. 


\section{TABELA 1 - CONDIÇÕES OPERACIONAIS DOS ENSAIOS, COMPARANDO PULVERIZADORES PARA VERIFICAÇÃO DA DEPOSIÇÃO DE AGROTÓXICOS EM VIDEIRA}

\begin{tabular}{l|c|c|c|c|c}
\hline \multirow{2}{*}{ Condi । es operacionais } & \multirow{2}{*}{ Testemunha } & \multicolumn{5}{|c}{ Pulverizadores com ventiladores modificados com } \\
& & \multicolumn{4}{|c}{ tomada de ar frontal } \\
\hline Equipamento & FMC-Uva & Airbus 200 & Airbus 500 & Airbus 200 & Airbus 500 \\
\cline { 2 - 6 } Bicos & Yamaho D3 & \multicolumn{3}{|c}{ JA-1 } & API 110-015 \\
\hline Press - o (kg/cmt) & 10,5 & 10,5 & 10,5 & 3,8 & 3,8 \\
Vaz o do ramal (L/min) & 11,5 & 6,9 & 5,1 & 9,9 & 9,6 \\
Tempo gasto (min/ha) & 52,0 & 53,33 & 47,9 & 50,6 & 52,1 \\
Volume (L/ha) & 600 & 372 & 246 & 501 & 503 \\
Calda - Rodamina (mg/L) & 45 & 54 & 50 & 55 & 65 \\
Dose geral (mg/ha) & 27000 & 20093 & 12308 & 27570 & 32437 \\
Temperatura ("C) & 27 & 29 & 28 & 28 & 27 \\
Umidade Relativa (\%) & 59 & 42 & 43 & 44 & 47 \\
Vento (m/s) & 2,0 & 4,1 & 0,1 & 1,4 & 3,5 \\
\hline
\end{tabular}

\section{RESULTADOS E DISCUSSÃO}

Trabalhos prévios com o traçador Rodamina $\mathrm{B}(6,7)$ demonstram que o método de extração com água e Tween 80 recupera $100 \%( \pm 3,3 \%)$ do produto aplicado em papel mata borrão. Os resultados desses trabalhos também comprovaram que o Fluorômetro Turner modelo 450 apresenta reposta linear para concentrações de Rodamina entre 0 e $100 \mu \mathrm{g} / \mathrm{L}$. Entretanto, para a avaliação do traçador nos experimentos utilizou-se Fluorômetro calibrado para leituras dentro da faixa de concentração entre 0 e $1000 \mu \mathrm{g} / \mathrm{L}$. Nesse caso, obteve-se correlação linear com coeficiente de correlação $R^{2}=0,9934$ para a equação de reta: $\mathbf{y}=1,0337 \mathbf{x}$, na qual $\mathbf{y}$ correspondeu a concentração real da solução e $\mathbf{x}$ ao valor observado no aparelho. Os valores das concentrações de todas as amostras do experimento foram corrigidos pela equação de calibração do Fluorômetro.

Devido aos diferentes volumes e concentrações de calda aplicados (Tabela 1) foi necessário transformar os valores das deposições, obtidas nas 100 parcelas, para depósitos equivalentes à aplicação de dose de $27000 \mathrm{mg}$ de Rodamina B por hectare. Nesse caso, a dose de $27000 \mathrm{mg} / \mathrm{ha}$ deve ser considerada como a deposição máxima teórica que poderia ser encontrada na videira se não houvesse nenhuma perda. Com os valores corrigidos foi realizada a análise estatística dos resultados (Tabela 2).

Comparando a deposição entre as regiões de amostragem (medias nas colunas da Tabela 2) verifica-se que a região basal da parreira (em que ficam os cachos) recebeu as maiores deposições de traçador. Tal fato pode ser esperado em virtude das características morfológicas das folhas da videira que apresentam áreas relativamente grandes e desenvolvem-se em plano horizontal. A diminuição gradativa da deposição para as regiões mediana e apical da latada, também é conseqüência da forma perpendicular com que o jato de ar, com as gotas, atinge a cobertura foliar da videira. As gotas são filtradas pelas camadas sucessivas de folhas formando o gradiente de deposição. Assim, as folhas da região apical da parreira recebem baixa concentração de produto. Como os principais problemas fitossanitários da videira são as doenças, esse fato pode contribuir para o reaparecimento de ataques de fungos ou para o aparecimento de raças resistentes aos fungicidas. A irregularidade na deposição em videira e em outras culturas $(4,5,6,8)$ não são proporcionadas por motivos necessariamente iguais. Entretanto, indicam a necessidade de ajustes na direção/velocidade do jato e tamanho das gotas de maneira que a camada de folhas mais expostas à pulverização não impeça a penetração dos agrotóxicos para o interior da cobertura foliar. 
TABELA 2 - DEPOSIÇÃO DE RODAMINA B (mg/m²) EM REGIÕES DA PLANTA E SOLO, PROPORCIONADA POR DIFERENTES BICOS E PULVERIZADORES

\begin{tabular}{|c|c|c|c|c|c|}
\hline \multirow{3}{*}{$\begin{array}{l}\text { REGI^ O DA } \\
\text { AMOSTRAGEM } \\
\text { parreira e solo }\end{array}$} & \multirow{3}{*}{$\begin{array}{c}\text { Testemunha } \\
\text { Yamaho D3,, } \\
\text { FMC-Uva† }\end{array}$} & \multicolumn{4}{|c|}{$\begin{array}{l}\text { Pulverizadores com ventiladores modificados com } \\
\text { tomada de ar frontal }\end{array}$} \\
\hline & & \multicolumn{2}{|c|}{ JA-1, } & \multicolumn{2}{|c|}{ AVI 110-015, } \\
\hline & & Airbus 200† & Airbus 500† & Airbus 200† & Airbus 500† \\
\hline Basal $\ddagger$ & в $1,56^{a}$ & A $1,99^{a}$ & ${ }_{A} 2,06^{a}$ & c $1,16^{a}$ & c $1,15^{a}$ \\
\hline Medianał & ${ }_{A} 0,91^{b}$ & ${ }_{A} 0,87^{b}$ & A $1,05^{b}$ & ${ }_{\mathrm{B}} 0,61^{\mathrm{b}}$ & ${ }_{\mathrm{B}} 0,63^{\mathrm{b}}$ \\
\hline Apicalł & ${ }_{\mathrm{B}} 0,45^{\mathrm{c}}$ & ${ }_{\mathrm{B}} 0,33^{\mathrm{c}}$ & ${ }_{\mathrm{A}} 0,78^{\mathrm{C}}$ & ${ }_{\mathrm{B}} 0,39^{\mathrm{b}}$ & ${ }_{\mathrm{B}} 0,44^{\mathrm{b}}$ \\
\hline Soloł & ${ }_{B} 0,13^{d}$ & ${ }_{A} 0,62^{b}$ & ${ }_{B} 0,23^{d}$ & ${ }_{A} 0,55^{c}$ & ${ }_{A} 0,53^{C}$ \\
\hline
\end{tabular}

1 Tipos de bicos.

${ }^{2}$ Em cada coluna, comparando cada pulverizador com as diferentes regiões de amostragem, médias seguidas por letras minúsculas iguais não diferem entre si pelo teste de Tukey ao nível de $5 \%$ de probabilidade.

3 Em cada linha, comparando cada região de amostragem com os diferentes bicos e pulverizadores, médias precedidas por letras maiúsculas iguais não diferem entre si pelo teste de Tukey ao nível de $5 \%$ de probabilidade.

Observou-se durante o teste de deposição do equipamento Airbus 200 com 14 bicos JA-1, que os jatos de quatro bicos (2 em cada extremidade do ramal do pulverizador) projetavam gotas num plano muito próximo da horizontal (sendo desperdiçadas para o solo). Provavelmente, o pulverizador Airbus 200 com ramal de bicos JA-1 estava calibrado de fábrica para cultura com porte mais baixo e, desta forma, os bicos laterais do ramal estavam desperdiçando o produto. Esse desperdício foi corrigido no pulverizador Airbus $500 \mathrm{com}$ bicos JA-1, desligando-se os dois bicos extremos de cada lateral do ramal. Assim, o volume de calda aplicado pelo pulverizador Airbus 500 com bicos JA-1 foi muito menor que dos demais. Entretanto, na comparação dos pulverizadores (entre as linhas da Tabela 2) observouse que o Airbus 500 com bicos JA-1 apresentou melhor deposição em todas as regiões das plantas com aplicação de apenas 246 litros de calda por hectare. Deve ser considerado que essa superioridade seria obtida se o equipamento estivesse aplicando 27000 miligramas de Rodamina B por hectare. Nesse caso, a concentração de sua calda deveria ser equivalente a 98 miligramas de Rodamina B por litro, ou seja, quase duas vezes mais concentrada que a calda original utilizada no teste. A superioridade dessa calibração pode ter sido conseqüência do pequeno tamanho de gotas produzidas pelo bico JA-1, que segundo o fabricante (10) apresentaria diâmetro mediano volumétrico de 68 micrômetros na pressão de $10,5 \mathrm{~kg} / \mathrm{cm}^{2}$. As gotas pequenas acompanham o movimento do ar, conseguindo alterar a trajetória quando encontram grandes objetos. Desta forma, o pulverizador Airbus 500 equipado com bicos JA-1 apresentou as maiores deposições nas três regiões de amostragem da parreira.

A inferioridade de deposição dos bicos API-110-015 resultou, provavelmente, do tamanho de gotas que (reconhecidamente) os bicos leques produzem (11), particularmente, quando submetidos à pressões reduzidas (Tabela 1). Com pressões reduzidas e o elevado ângulo de abertura do jato, as gotas perdem a velocidade de arremesso rapidamente ficando sujeitas a ação exclusiva do vento do ventilador do pulverizador.

A comprovação da superioridade do pulverizador Airbus 500 com bicos JA-1 pode ser observada na Tabela 3, estabelecida a partir da média geral de deposição na planta e os valores da Tabela 2 (equação 1).

Porcentagem $/$ Planta $=[($ Deposição Apical + Deposição Mediana + Deposição Basal $) / 3 \times 17000] /$ $27000 \times 100$. 
Na qual: $17000=$ a área foliar $\left(\mathrm{m}^{2}\right)$ e $27000=$ dose $(\mathrm{mg})$ de Rodamina B aplicada por hectare.

A porcentagem encontrada no solo foi estabelecida a partir da equação 2:

porcentagem/solo = deposição solo $\times 10000 / 27000 \times 100$.

Na qual: $10000=$ área de um hectare $\left(\mathrm{m}^{2}\right)$.

O percentual de evaporação ou deriva foi estabelecido pela diferença entre a porcentagem total e as encontradas nas plantas e no solo.

TABELA 3 - DISTRIBUIÇÃO PERCENTUAL DE TRAÇADOR EM VIDEIRAS, COMPARANDO DIFERENTES BICOS E PULVERIZADORES

\begin{tabular}{|c|c|c|c|c|c|}
\hline \multirow{3}{*}{ Local da deposi ${ }^{a} 0$} & Testemunha & \multicolumn{4}{|c|}{$\begin{array}{c}\text { Pulverizadores com ventiladores modificados com } \\
\text { tomada de ar frontal }\end{array}$} \\
\hline & FMC-Uva & Airbus 200 & Airbus 500 & Airbus 200 & Airbus 500 \\
\hline & Yamaho D3,, & \multicolumn{2}{|c|}{$\mathrm{JA}-1}$, & \multicolumn{2}{|c|}{ AVI 110-015, } \\
\hline Planta & 61 & 67 & 82 & 46 & 47 \\
\hline Solo & 5 & 23 & 8 & 20 & 19 \\
\hline Evapora ${ }^{a}$ o/deriva & 34 & 10 & 10 & 34 & 34 \\
\hline
\end{tabular}

${ }^{1}$ Tipos de bicos utilizados.

A tomada de ar frontal dos pulverizadores Airbus não promoveu redução na perda de produto para o solo, quando comparado com o pulverizador FMC (Tabela 3). Entretanto, o pulverizador FMC apresentou razoável perda por evaporação/deriva, como provável conseqüência da aspiração de gotas pelo ventilador do equipamento.

As perdas para o solo verificadas por PERGHER, GUBIANI e TONETTO (2) foram superiores às obtidas para todos os pulverizadores (Tabela 3 ), porque seus testes foram realizados em videiras cultivadas na forma de espaldeira.

Os pulverizadores, Airbus 200 e Aibus 500 (com 14 bicos leque API 110 015) operaram com pressão de $3,8 \mathrm{~kg} / \mathrm{cm}^{2}$, enquanto que o FMC UVA (com 10 bicos leques Yamaho D3) com 10,5 kg/cm² (Tabela 1). Assim, tanto o número de bicos como a pressão de trabalho podem ter influenciado nas diferentes deposições obtidas com esses equipamentos (Tabela 3). Dividindo-se a vazão total do equipamento pelo seu número de bicos (Tabela 1) verificou-se que a taxa de pulverização de cada bico Yamaho D3 foi de 1,15 L/min, enquanto a dos API-110-015 foi de 0,70 L/min. Apesar de pulverizar com vazão aproximadamente 40\% superior ao bico API-110-015, o bico Yamaho D3 estava submetido a pressão aproximadamente $276 \%$ mais elevada e, provavelmente, por essa razão suas gotas eram menores. Assim, o ventilador do equipamento FMC conseguiu assoprar as pequenas gotas do bico Yamaho com maior eficiência que os pulverizadores Airbus 200 e 500 com bicos API.

Os tamanhos das gotas do Bico API-110-015, submetidos a pressões de 2,1 e $3,2 \mathrm{~kg} / \mathrm{cm}^{2}$ seriam de 159 e 139 micrômetros respectivamente (11). Nesse caso, o aumento de $\pm 33 \%$ na pressão foi responsável pela redução de aproximadamente $13 \%$ no tamanho das gotas. A empresa Jacto S/A (11) não apresentou o diâmetro de gotas do bico API para pressão de $3,8 \mathrm{~kg} / \mathrm{cm}^{2}$, mas se fossem obedecidas as devidas proporções, o tamanho das gotas produzidas não seria inferior a 100 micrômetros.

O tempo de vida, em segundos, de uma gota de água é dada pela seguinte fórmula (1): $\mathrm{t}=\mathrm{d}^{2} / 80 \Delta \mathrm{T}$, na qual $\mathbf{d}$ é o diâmetro da gota em micrômetros e $\Delta \mathrm{T}$ a diferença de temperatura $\left({ }^{\circ} \mathrm{C}\right)$ entre 
termômetros de bulbo seco e úmido. Considerando as condições de temperatura e de umidade relativa (pelo psicrômetro Assman, $\Delta T=9^{\circ} \mathrm{C}$, para $U R=44 \%$ e $\Delta T=8{ }^{\circ} \mathrm{C}$ para $U R=47 \%$ ) para os testes dos bicos API-110-015 verifica-se que uma gota de 100 micrômetros teria tempo de vida entre 16 e 14 segundos para os pulverizadores Airbus 200 e 500, respectivamente. As distâncias (cm) que essas gotas conseguiriam percorrer antes da extinção total podem ser calculadas pela seguinte fórmula (1): $\mathrm{D}=\left(1,5 \times 10^{-3} \times \mathrm{d}^{4}\right) / 80 \Delta \mathrm{T}$. Assim, gotas de 100 micrômetros nas condições meteorológicas em que foram realizados os testes dos equipamentos Airbus 200 e 500, com bicos AVI-110-015, conseguiriam atingir distâncias de 2,4 m e 2,1 m, respectivamente. Nesse caso, o jato de gotas lançado pelo ventilador do pulverizador apresentava forma de leque e parte do vento ao se chocar com a massa de folhas da videira, desviou-se para as laterais levando parte das gotas. Essas gotas, ao assumirem movimento horizontal podem ter perdido água por evaporação. Outro fato importante é que muitas gotas que atingiram movimento vertical conseguiram de alguma forma ultrapassar a camada de folhas para se depositar em fina tela de nylon preto que recobria a latada, justificando as perdas de $34 \%$ apresentadas na Tabela 3.

O tamanho das gotas produzidas pelo Bico JA-1 foi de 68 micrômetros (10) para a pressão de $10,5 \mathrm{~kg} / \mathrm{cm}^{2}$. Nesse caso, considerando as condições de temperatura e umidade relativa do ensaio $(\Delta \mathrm{T}=9 \stackrel{\circ}{\circ}$ ), o tempo de vida dessas gotas seria de aproximadamente 6,4 segundos e a distância percorrida de aproximadamente $0,5 \mathrm{~m}$. Com as fórmulas de volume e superfície de esfera (6) seria possível estimar que um litro de calda produziria aproximadamente 5.652.929.042 gotas de 68 micrômetros de diâmetro. Portanto, a superfície total dessas gotas seria de aproximadamente $21 \mathrm{~m}^{2}$. O pulverizador Airbus $200 \mathrm{com}$ bico JA-1 estaria lançando 39.570.503.295 gotas por minuto ou, aproximadamente, $7 \mathrm{~L} / \mathrm{min}$ com $144 \mathrm{~m}^{2}$ de superfície de exposição. O pulverizador Airbus 500 estaria lançando 28.264.645.211 gotas por minuto ou, aproximadamente, $5 \mathrm{~L} / \mathrm{min}$ com $103 \mathrm{~m}^{2}$ de superfície de exposição. A baixa porcentagem de evaporação (Tabela 3), verificada nos testes com esses bicos, pode ser explicada pela rápida saturação de umidade do interior da nuvem com elevadíssima quantidade de gotas. Considerando o tempo que o pulverizador Airbus $500 \mathrm{com}$ bicos JA-1 gastou para tratar um hectare (47,9 min), a velocidade de deslocamento do trator seria de $1,4 \mathrm{~m} / \mathrm{s}$. Considerando que a faixa tratada era 2,5 m e se os bicos estivessem passando a 0,5 $\mathrm{m}$ de distância da região basal da parreira, o volume de ar que estaria recebendo as gotas seria de $1,75 \mathrm{~m} 3 / \mathrm{s}$. Se as gotas produzidas por segundo ficassem uniformemente distribuídas no espaço pulverizado existiriam $269.187 .097 \mathrm{gotas} / \mathrm{m}^{3}$ ou 269 gotas $/ \mathrm{cm}^{3}$ de ar, ou seja, a saturação de umidade entre as gotas seria rápida com pequena perda de volume de cada gota. A evaporação das gotas dentro da nuvem poderia estar proporcionando, instantaneamente, redução de temperatura e saturação da umidade relativa do ar. A alta umidade relativa dentro da nuvem de gotas poderia garantir maior tempo de vida para a deposição na planta ou no solo. Deve ser considerado que a própria estrutura da latada da parreira, recoberta com tela fina, contribuiu para uma proteção contra ventos, que poderiam alterar o microclima instantâneo criado pela nuvem de gotas. Para efeito de comparação, caso os bicos API 110-015 estivessem pulverizando gotas de 100 micrômetros estariam lançando 3 vezes menos gotas por litro que os bicos cones. Considerando as vazões apresentadas na Tabela 1, também estariam lançando $47 \%$ a $65 \%$ menos gotas que os bicos JA-1. Nesse caso, a saturação de umidade dentro da nuvem de gotas produzidas pelos bicos API seria menor que a dos bicos JA-1, não só devido ao menor número de gotas, mas também pela menor superfície de exposição.

\section{CONCLUSÃO}

A deposição do traçador Rodamina B foi maior na região basal da cobertura foliar da videira cultivada em latada, decrescendo significativamente para as regiões superiores da parreira. $O$ pulverizador Jacto Airbus 500 equipado com 10 bicos JA-1 apresentou os melhores resultados de 
deposição do traçador na planta, aplicando 246 litros de calda/ha. A posição frontal para tomada de ar do ventilador dos pulverizadores não reduziu a perda de produtos para o solo.

\section{ABSTRACT}

\section{THE VINEYARD SPRAYING DEPOSITION EFFICIENCY, COMPARING NOZZLES AND SPRAYERS}

The deposition of pesticides in vineyard given by different types of sprayers and nozzles was studied. Two types of sprayers with frontal air aspiration fan (Airbus 200 and Airbus 500, manufactured by Jacto) were compared with traditional ventilation sprayers. The traditional spray was regulated with JA-1 or API-110-015 nozzles. In order to evaluate the sprayers deposition efficiency, Rodamine B was used as tracer. The equipment Jacto Airbus 500, equipped with 10 nozzles JA -1 , regulated to apply $246 \mathrm{~L} /$ ha was the most effective, depositing $82 \%$ of product in the plant, with $8 \%$ losses to the soil and $10 \%$ by evaporation or drift.

KEY-WORDS: TRACER; PESTICIDE; SPRAYING EQUIPMENT.

\section{REFERÊNCIAS}

1 MATTHEWS, G.A. Pesticide application methods. New York: Longman, 1982. 336 p

2 PERGHER, G.; GUBIANI, R.; TONETTO, G. Foliar deposition and pesticide losses from three air-assisted sprayers in a hedgerow vineyard. Crop protection, Oxford, v.16, n.1, p.25-33, 1997.

3 PERGHER, G.; GUBIANI, R. The effect of spray application rate on foliar deposition in a hedgerow vineyard. Journal of Agricultural Engineering Research, London, n.61, p. 205-216, 1995.

4 CHAIM, A.; CASTRO, V. L. S. S.; CORRALES, F. M.; GALVÃO, J. A. H.; CABRAL, O. M. R.; NICOLELLA, G. Método para monitorar perdas na aplicação de agrotóxicos na cultura do tomate. Pesquisa Agropecuária Brasileira, Brasília, v.34, n.5, p.741 - 747, 1999.

5 CHAIM, A.; VALARINI, P.J.; OLIVEIRA, D.A.; MORSOLETO, R.V.; PIO, L.C. Avaliação de perdas de pulverização em culturas de feijão e tomate. Jaguariúna: Embrapa Meio Ambiente, 1999. 29 p. (Embrapa Meio Ambiente, Boletim de Pesquisa, 2).

6 SCRAMIN, S.; CHAIM, A.; PESSOA, M. C. P. Y.; FERRACINI, V. L.; ANTÔNIO, P. L.; ALVARENGA, N. Avaliação de bicos de pulverização de agrotóxicos na cultura do algodão. Pesticidas: Revista de Ecotoxicologia e Meio Ambiente, Curitiba, v.12, p.43 - 50, 2002.

7 FERRACINI, V.L.; CHAIM, A.; PESSOA, M.C.P.Y. Utilização da Rodamina B como traçador na avaliação de deposição de agrotóxicos. In: CONGRESO VIRTUAL IBEROAMERICANO SOBRE GESTIÓN DE CALIDAD EN LABORATORIOS, 2., Valladolid, 2004. Libro de comunicaciones... Valladolid: Instituto Tecnológico Agrario de Castilla y León, 2004. p. 467-472.

8 CHAIM, A.; BOTTON, M.; SCRAMIN, S.; PESSOA, M. C. P. Y.; SANHUEZA, R. M. V.; KOVALESKI, A. Deposição de agrotóxicos pulverizados na cultura da maçã. Pesquisa Agropecuária Brasileira, Brasília, v.38, n.7, p.889-892, 2003.

9 BANZATO D.A.; KRONCA, S.N. Experimentação agrícola. 3.ed. Jaboticabal: FUNEP, 1995. 247 p.

10 JACTO S/A. Bicos série JA: cone vazio. Pompéia, 1999. 2 p.

11 JACTO S/A. Bicos Jacto-API. Pompéia, 2001. 2 p. 